\title{
FATORES PREDITORES DE MALIGNIDADE EM NEOPLASIAS DE CÉLULAS DE HURTHLE
}

\author{
PREDICTOR FACTORS OF MALIGNANCY IN HÜRTHLE CELL NEOPLASMS
}

\author{
Carlos Augusto Fischer¹; Agnaldo José Graciano²; Sérgio José Ferreira TCBC-SC ${ }^{3}$; \\ Carlos Antônio Daudt ${ }^{4}$; Cleber Antonio Fiorini5 ${ }^{5}$ Karina Silvestri $^{5}$
}

\begin{abstract}
RESUMO: Objetivo: neoplasias de células de Hurthle são tumores da glândula tireóide de baixa incidência que apresentam muitas controvérsias quanto à distinção entre carcinomas e adenomas. O objetivo deste estudo foi identificar fatores preditores de malignidade neste tipo específico de neoplasia. Métodos: entre janeiro de 1999 e junho de 2006, 56 casos de neoplasia de células de Hurthle foram diagnosticados em nossa instituição e foram estudados retrospectivamente. Resultados: trinta e sete pacientes apresentaram diagnóstico patológico de adenoma de células de Hurthle (ACH), enquanto 19 casos foram diagnosticados como carcinoma de células de Hurthle $(\mathrm{CCH})$. No grupo de pacientes com adenomas a idade média foi de 47,8 anos, sendo que trinta e cinco $(94 \%)$ eram do sexo feminino e apenas dois $(5,5 \%)$ casos do sexo masculino. O tamanho médio dos adenomas foi de $2,1 \mathrm{~cm}$ variando de 0,3 a $6,0 \mathrm{~cm}$. Entre os 19 casos de carcinomas a média de idade foi de 51,1 anos, sendo quatorze casos em mulheres (73\%) e cinco em homens (26,4\%). O tamanho médio dos nódulos neste grupo foi de 3,8 cm, variando de 2,0 cm a 7,5 cm. Conclusão: Pacientes com neoplasias de células de Hurthle apresentando nódulos maiores que três centímetros, principalmente em homens, apresentam maior risco de malignidade (Rev. Col. Bras. Cir. 2008; 35(4): 221-224).
\end{abstract}

Descritores: Tireoidectomia; Neoplasias das glândulas tireóides; Adenoma oxífilo.

\section{INTRODUÇÃO}

Neoplasia de células de Hurthle, ou tumores de células oxifílicas descrito primeiramente por Ewing em 1928, é uma doença pouco comum representando $4,5 \%$ a $10 \%$ dos tumores diferenciados da tireóide ${ }^{1,2}$. Histologicamente caracterizase pela presença de grandes células foliculares poligonais com citoplasma granular acidófilo repleto de mitocôndrias ${ }^{3}$.

Assim como as neoplasias foliculares, usualmente são descobertas por exame citológico de material obtido através de punção aspirativa com agulha fina (PAAF) durante investigação de nódulos da tireóide. A distinção entre carcinoma e adenoma é em geral somente obtida no período pósoperatório através de exame histopatológico do espécime cirúrgico. Invasão capsular ou vascular, presença de metástases para linfonodos ou à distância são critérios utilizados para o diagnóstico de carcinoma ${ }^{4-7}$. A correta diferenciação dos carcinomas de células de Hurthle $(\mathrm{CCH})$ é importante pois este grupo apresenta maior agressividade que os carcinomas foliculares com maior incidência de metástase linfonodal e à distância , principalmente para o pulmão, e além disso, os $\mathrm{CCH}$ têm menor capacidade de absorver o Iodo radioativo tornando a terapia adjuvante com Iodo menos eficiente ${ }^{8-11}$.
A distinção entre carcinomas e adenomas através do exame de congelação trans-operatório ou através da PAAF é muito difícil, sendo impossível na maioria dos casos. O objetivo deste estudo é identificar fatores preditores de malignidade em uma série de 56 pacientes com neoplasias de células de Hurthle.

\section{MÉTODO}

Durante o período de janeiro de 1999 a junho de 2006 foram realizadas 1112 tireoidectomias em pacientes com diferentes doenças da glândula tiróide em nosso serviço. Destes, $56(5 \%)$ foram diagnosticados como neoplasias de células de Hurthle e foram estudados retrospectivamente.

Neoplasia de células de Hurthle foi definida como uma lesão da tireóide encapsulada composta de pelo menos $75 \%$ de células oxifílicas. Os critérios de Livolsis de invasão vascular e ou capsular foram utilizados para o diagnóstico de carcinoma de células de Hurthle ${ }^{7}$.

Todos pacientes foram avaliados no ambulatório de Cirurgia de Cabeça e Pescoço e submetidos à ultra-sonografia (US) da tireóide, e PAAF guiada ou não por ultra-sonografia foi realizada em todos os pacientes com nódulo identificados

\footnotetext{
1. Preceptor do Serviço de Cirurgia Geral Hospital Municipal São José, Joinville - SC; Cirurgião de Cabeça e Pescoço.

2. Mestre em Otorrinolaringologia - Cirurgia de Cabeça e Pescoço pela Unifesp; Preceptor do Serviço Cirurgia Geral - Hospital Municipal São José, Joinville - SC.

3. Coordenador do Departamento de Cirurgia Geral do Hospital Municipal São José, Joinville - SC.

4. Doutor em Pneumologia pela UFRGS; Coordenador da Residência Médica do Hospital Municipal São José, Joinville - SC; Professor Univille Cadeira Cirurgia Torácica.

5. Residente de Cirurgia Geral do Hospital Municipal São José, Joinville- SC.
}

Recebido em 17/12/2007

Aceito para publicação em 20/03/2008

Conflito de interesses: nenhum

Fonte de financiamento: nenhuma

Trabalho realizado no Departamento de Cirurgia Hospital Municipal São José, Joinville -SC. 
por US ou palpáveis. O envolvimento de linfonodos foi avaliado através de ultra-sonografia e exame físico. Espécimes de tecido foram rotineiramente submetidos à analise patológica após exérese cirúrgica de parte ou de toda a glândula tireóide.

Os prontuários médicos foram revisados e a comparação dos dois grupos envolveu a avaliação dos dados demográficos de sexo e idade, história médica, tamanho do tumor (exame histopatológico), associação com outras doenças benignas da tireóide, presença concomitante de outros tipos de câncer de tireóide, e avaliação dos dados referentes à PAAF.

Para a análise estatística, o teste $\mathrm{t}$ de Student e o teste exato de Fischer foram empregados para avaliar possível significância entre os dados obtidos e a ocorrência de adenoma ou carcinoma de células de Hurthle. As diferenças foram consideradas estatisticamente significativas quando $\mathrm{p}<0.05$.

\section{RESULTADOS}

Foram estudados retrospectivamente 56 casos de neoplasia de células de Hurthle. Trinta e sete pacientes apresentaram adenoma de células de Hurthle (66\%) enquanto 19 casos foram diagnosticados como $\mathrm{CCH}(34 \%)$. Entre os adenomas, a maioria dos casos ocorreu em mulheres $(n=35$ / $94,5 \%)$, e apenas dois pacientes $(5,5 \%)$ eram do sexo masculino. A média de idade foi de 47,8 anos variando de 13 a 74 anos. Neste grupo pudemos aferir o tamanho dos nódulos em 30 casos $(81 \%)$, sendo que a média foi de $2,1 \mathrm{~cm}$ variando de 0,3 a $6,0 \mathrm{~cm}$. A doença mais freqüentemente associada à ocorrência de adenoma de células de Hurthle foi a presença de bócio adenomatoso $(n=6 / 16,2 \%)$, seguida por tireoidite de Hashimoto $(n=4 / 10,8 \%)$ e carcinoma papilífero em outros dois casos $(5,4 \%)$.

No grupo de pacientes com carcinoma, $14(73,6 \%)$ pacientes eram mulheres e cinco $(26,4 \%)$ homens. A média de idade foi de 51,1 anos, variando de 25 a 79 anos. O tamanho médio dos nódulos dos pacientes com carcinoma de células de Hurtlhe foi de $3,8 \mathrm{~cm}$, variando de 2,0 cm a 7,5 cm. Diagnósticos associados à $\mathrm{CCH}$ foram tireoidite de Hashimoto em dois pacientes $(10,5 \%)$, adenoma folicular em um caso $(5,2 \%)$ e carcinoma papilífero em um paciente $(5,2 \%)$.

Os dados da punção aspirativa dos pacientes com neoplasias de células de Hurthle são demonstrados na tabela 1.

Ressalta-se que nesta série foram avaliados sete pacientes do sexo masculino e destes, cinco $(71,4 \%)$ eram porta- dores de carcinoma e apenas dois $(28,6 \%)$ eram portadores de adenomas.

O teste $t$ de Student e o teste exato de Fischer avaliaram a correlação estatística entre o tamanho do nódulo na macroscopia e a presença de carcinoma ou adenoma. Também foi utilizado o mesmo teste para avaliar a correlação estatística entre idade e presença de carcinoma e adenoma. $\mathrm{O}$ teste demonstrou que há significância estatística direta entre tamanho do tumor e presença de carcinoma de células de Hurthle (Tabela 2). A idade não demonstrou ser estatisticamente relevante para presença de carcinoma ou adenoma.

\section{DISCUSSÃO}

Neoplasia de células de Hurthle frequentemente é considerada uma variante da neoplasia de células foliculares e muitas controvérsias existem em relação à diagnóstico, comportamento biológico, e tratamento ${ }^{12}$. A distinção entre carcinoma e adenoma somente é obtida no pós-operatório através da análise patológica do espécime cirúrgico, gerando dúvidas se o tratamento cirúrgico realizado foi completo. A identificação de fatores preditores de malignidade no pré-operatório pode auxiliar na decisão cirúrgica.

Tumores de células de Hurthle podem ser diagnosticados por PAAF, entretanto, distinção entre carcinoma e adenoma não é possível. Sugino et al consideraram este um método insatisfatório para o diagnóstico de neoplasia de Hurthle, pois observaram que apenas $38 \%$ dos seus casos, foram diagnosticados como lesão de células de Hurthle pela PAAF. Em nossa série, 39 casos foram submetidos à PAAF e o diagnóstico de lesão de células de Hurthle foi obtido em 20 casos $(51 \%)^{13}$. Entretanto, Hawasli et al consideraram que a

Tabela 1 - Resultado punção aspirativa com agulha fina quanto à diferenciação em carcinoma x adenoma, em porcentagem.

\begin{tabular}{lcc}
\hline & Carcinoma (\%) & Adenoma (\%) \\
\hline Com PAAF & 73,6 & 67,5 \\
Sem PAAF & 26,4 & 32,5 \\
Diagnóstico & & \\
Lesão células Hurthle & 42,0 & 56,0 \\
Lesão folicular & 42,0 & 28,0 \\
Bócio & 7,0 & 8,0 \\
Acelular & 7,0 & 8,0 \\
\hline
\end{tabular}

Tabela 2 - Características do tumor.

\begin{tabular}{lccccc}
\hline & Carcinomas & Adenomas & Sensibilidade & Especificidade & P \\
\hline Tumores mensuráveis & $\mathrm{N}=16$ & $\mathrm{~N}=30$ & & & \\
Tamanho médio $(\mathrm{cm})$ & 3,8 & 2,1 & & & \\
Tumor $=1 \mathrm{~cm}$ & $16(100 \%)$ & $27(90 \%)$ & $100 \%$ & $30 \%$ & $0,54(\mathrm{~ns})$ \\
Tumor $=2 \mathrm{~cm}$ & $16(100 \%)$ & $13(43 \%)$ & $100 \%$ & $54 \%$ & $0,001(\mathrm{~S})$ \\
Tumor $=3 \mathrm{~cm}$ & $11(68 \%)$ & $7(23 \%)$ & $73 \%$ & $70 \%$ & $0,004(\mathrm{~S})$ \\
\hline
\end{tabular}

$N S$ - não significativo; $S$ - significativo. 
PAAF poderia ser usada como fator preditor de malignidade quando o achado fosse de neoplasia folicular ou Hurthle, uma vez que $85 \%$ dos seus casos com esse achado na citologia eram malignos ${ }^{6}$. Porém, em nosso estudo, encontramos uma incidência de $30 \%$ de carcinomas em 56 casos estudados.

Vários autores têm relatado diferentes características clínicas dos carcinomas e adenomas ${ }^{5,12,13}$. Carcangiu et al ${ }^{3}$ relataram que pacientes com câncer têm um tumor primário maior e Chen et al ${ }^{14}$ descreveram que o tamanho do tumor primário tem valor preditivo como critério para malignidade, embora alguns autores não confirmem isso. No presente estudo, $68 \%$ e $100 \%$ dos carcinomas tinham mais que 3 e $2 \mathrm{~cm}$ respectivamente, enquanto a maioria dos adenomas (57\%) eram menores que $2 \mathrm{~cm}$. A sensibilidade e a especificidade para o diagnóstico de $\mathrm{CCH}$ em tumores maiores ou igual a $2 \mathrm{~cm}$ foi de $100 \%$ e $54 \%$ respectivamente. Quando os tumores eram maiores ou igual a $3 \mathrm{~cm}$ a sensibilidade diminuiu para $73 \%$, entretanto, a especificidade aumentou para $70 \%$. O risco de carcinoma aumentou claramente com o tamanho do tumor, sugerindo que este seja um critério para determinar a extensão da tireoidectomia.

A neoplasia de célula de Hurthle é infreqüente em crianças e adolescentes, ocorrendo geralmente entre a $5^{\mathrm{a}}$ e $6^{\mathrm{a}}$ décadas de vida ${ }^{15}$. Lopez-Penabad et al também observaram uma clara diferença de idade em sua série, entre os adenomas e carcinomas, sendo os últimos nove anos mais velhos ${ }^{4}$. Esses achados não são consistentes com nosso estudo com média de idade de 51,1 anos para os adenomas e 47,7 anos para os casos de carcinoma, não havendo diferença estatisticamente significante.

Em pacientes submetidos à operação para ressecção de nódulos tireoidianos com achados citológicos indeterminados. O sexo, geralmente, não é considerado um fator para diferenciar tumores benignos de malignos. Em nos- sa casuística, a neoplasia de células de Hurthle ocorreu mais frequentemente em mulheres. Entretanto, a proporção de câncer foi mais elevada em homens. Dos 56 casos, 49 eram do sexo feminino e apenas sete masculinos. Entre estes, cinco $(71,5 \%)$ eram carcinomas. Dahl et al relataram em sua série dados semelhantes evidenciando forte associação entre carcinoma e sexo masculino em tumores de células de Hurthle. $\mathrm{Na}$ sua série sessenta e sete por cento dos pacientes masculinos apresentavam carcinoma, enquanto apenas 36\% das mulheres tinham o mesmo diagnóstico ${ }^{12}$.

A prevalência de malignidade entre as neoplasias de células de Hurthle na literatura pode chegar a 56\%. Alguns autores recomendam a tireoidectomia total para todos os casos devido ao possível comportamento mais agressivo da neoplasia de células de Hurthle e a freqüência mais elevada de carcinoma em algumas séries, aumentando a morbidade nesses pacientes ${ }^{16,17,18}$. Neste estudo, o adenoma foi mais prevalente, representando $70 \%$ dos casos enquanto carcinoma representou $30 \%$ da amostra, prevalência semelhante à maioria das séries. Assim, a extensão da tireoidectomia deve ser orientada utilizando-se fatores preditores de malignidade, com o intuito de diminuir a morbidade nesses pacientes.

A neoplasia de células de Hurthle é uma doença pouco comum e a distinção entre carcinoma e adenoma apresenta muitas dificuldades no pré- operatório e trans-operatório, complicando a escolha do melhor tratamento cirúrgico. Nódulos tireoidianos com PAAF pré-operatória diagnosticada como neoplasia de células de Hurthle e apresentando tamanho maior que $3 \mathrm{~cm}$, principalmente em homens, apresentam maior risco de malignidade. Os dados não nos permitem considerar a possibilidade de tireoidectomia total a partir destes achados, mas sugerem que estes pacientes necessitam de diagnóstico histológico precoce para decisão terapêutica definitiva.

\begin{abstract}
Background: Hürthle cell neoplasms are uncommon thyroid gland tumors that present a diagnostic challenge due to difficulties to differentiate between adenomas and carcinomas. The purpose of this study is to identify preoperative predictor factors of malignancy. Methods: A retrospective study of patients and tumor characteristics of 56 Hürthle cell tumors cases diagnosed in our institution between January 1999 and June 2006 was done. Results: Thirty-seven patients presented with adenoma, 35 women (94.5\%) and 2 men (4.5\%) with average age of 47.8 years. Medium tumor size in this group was $2.1 \mathrm{~cm}$ (ranging from 0.3 to $6.0 \mathrm{~cm}$ ). Nineteen patients with Hürthle cell carcinoma were found in this series with 14 (73\%) female and 5 male patients with average age of 51.1 years. Tumor size in this group ranged between 2.0 and $7.5 \mathrm{~cm}$ (medium of $3.8 \mathrm{~cm}$ ). Conclusion: Patients with Hürthle cell neoplasm nodules larger than $3.0 \mathrm{~cm}$, in the greatest diameter, especially in male patients, are predictor factors of having malignancy.
\end{abstract}

Key words: Thyroidectomy; Thyroid neoplasms; Adenoma, oxyphilic.

\section{REFERÊNCIAS}

1. Maxwell El, Palme CE, Freeman J. Hürthle cell tumors: applying molecular markers to define a new management algorithm. Arch Otolaryngol Head Neck Surg. 2006;132(1):54-8.

2. Chao TC, Lin JD, Chen MF. Surgical treatment of Hürthle cell tumors of the thyroid. Word J Surg. 2005;29(2):164-8.

3. Carcangiu ML. Hürthle cell carcinoma: clinic-pathological and biological aspects. Tumori. 2003; 89(5):529-32.
4. Lopez-Penabad L, Chiu AC, Hoff AO, Schultz P, Gaztambide S, Ordoñez NG, Shermana SI. Prognostic factors in patients with Hürthle cell neoplasms of the thyroid. Cancer. 2003;19(10):118694.

5. Pisanu A, Sias L, Uccheddu A. Factors predicting malignancy of Hürthle cell tumors of the thyroid: influence on surgical treatment. World J Surg. 2004;28(8):761-5. Epub 2004 Aug 3.

6. Hawasli A, Rizzo P, Khoury H, McCaffrey JL. Can fine-needle aspiration biopsy of thyroid nodule help in determining the extent 
of surgery in follicular and Hürthle cell neoplasm at a community teaching institution? Am Surg. 2002;68(10):907-10.

7. Livolsi VA. Surgical pathology of the thyroid. Philadelphia: WB Sauders; 1990

8. Masood S, Auguste L, Westerband A, Belluco C, Valderama E, Attie J. Differential oncogenic expression in thyroid follicular and Hürthle cell carcinomas. Am J Surg. 1993;166(4):366-8.

9. Hay I, Grant CS, van Heerden JA, Goellner JR, Ebersold JR, Bergstralh EJ. Papillary thryroid microcarcinoma: a study of 535 cases observed in 50-year period. Surgery. 1992;112(6):113946; discussion 1146-7.

10. McIvor NP, Freeman JL, Rosen I, Bedard YC. Value of fineneedle aspiration in the diagnosis of Hürthle cell neoplasms. Head Neck. 1993;15(4)335-41.

11. Yen TC, Line HD, Lee CH, Change SL, Yeh SH. The role of technetium-99m sestamibi whole-body scans in diagnosing metastatic Hürthle cell carcinoma of the thyroid gland after total thyroidectomy: a comparison with iodine-131 and thallium-201 whole body scans. Eur J Nucl Med. 1994;21(9):980-3.

12. Dahl LD, Myssiorek D, Heller KS. Hurthle cell neoplasms of the thyroid. Laryngoscope. 2002;112(12):2178-80.

13. Sugino K, Ito K, Mimura T, Kameyama K, I Hiroyuki, I Kunihiko. Hürthle cell tumor of the thyroid: analysis of 188 cases. World J Surg. 2001;25(9):1160-3.

14. Chen H, Nicol TL, Zeiger MA, Dooley WC, Ladenson PW, Cooper DS, et al. Hürthle cell neoplasms of the thyroid: are there factors predictive of malignancy? Ann Surg. 1998;227(4):542-6.
15. Kushchayeva Y, Duh QY, Kebebew E, Clark OH. Prognostic indications for Hürthle cell cancer. World J Surg. 2004;28(12):1266-70. Epub 2004 Nov 11.

16. Haigh PI, Urbach DR. The treatment and prognosis of Hürthle cell follicular thyroid carcinoma compared with its non-Hürthle cell counterpart. Surgery. 2005;138(6):1152-7; discussion 11578.

17. Paunovic I, Krgovic K, Tatic S, Diklic A, Zivaljevic V, Kalezic N, Halvelka M. Surgery for thyroid Hürthle cell tumors-a single institution experience. Eur J Surg Oncol. 2006;32(4):458-61.

18. Bhattacharyya N. Survival and prognosis in Hürthle cell carcinoma of the thyroid gland. Arch Otolaryngol Head Neck Surg. 2003;129(2):207-10.

Como citar este artigo:

Fischer CA, Graciano AJ, Ferreira SJ, Daudt CA, Fiorini CA, Silvestri K. Fatores preditores de malignidade em neoplasias de células de Hürthle. Rev Col Bras Cir. [periódico na Internet] 2008; 35(4). Disponível em URL: http://www.scielo.br/rcbc

Endereço para correspondência:

Carlos Augusto Fischer

Rua Campos Salles, 92 - Fundos

Bairro Glória

89217-100 - Joinville SC

E-mail: Carfis@terra.com.br 